\title{
Achtergronden bij de Richtlijn voortgangsgesprek in de medische vervolgopleiding
}

\section{Waarom een voortgangsgesprek?}

Het voortgangsgesprek heeft als doel het coachen van het leren van de aios. Kijken we naar de 'evidence' rond coaching en mentoring dan zien we een positieve relatie tussen mentoring/coaching en carrièresucces $^{2}$, productiviteit ${ }^{3}$, job satisfaction $^{4}$, beroepsvoorbereiding ${ }^{5}$ en leren in de werkplaats. ${ }^{6}$ De opleider begeleidt de aios over langere tijd waarbij niet alleen het leren, maar ook meer langetermijndoelen als carrièreontwikkeling aan bod komen. Bij de meeste studies gebeurt de begeleiding op vrijwillige basis. Minder duidelijk is wat het betekent als opleider en aios verplicht over langere tijd met elkaar voortgangsgesprekken voeren. Onderzoek zal meer inzicht moeten bieden in wat de combinatie van het verplichte karakter, de longitudinaliteit en de dubbelrol van de opleider als begeleider en beoordelaar ${ }^{7}$ voor effect heeft.

Een studie van Teunissen et al. ${ }^{8}$ laat zien dat reflectie een belangrijke rol speelt bij het leren van klinische ervaringen door aios. Ook het onderzoek op het terrein van expertiseontwikkeling ${ }^{9}$, het opleiden van verpleegkundigen ${ }^{10}$ en het opleiden van leraren onderstreept het belang van reflectie voor het leren op de werkplek. Reflectie kan worden gedefinieerd als 'het laten leiden van toekomstig gedrag door een systematische en kritische analyse van ervaringen en opvattingen'. ${ }^{11}$ Kritische zelfbeoordeling en het onderkennen van leerbehoeften zijn een voorwaarde voor reflectie. Door onbekendheid met reflectie bij de aios, en door een leerklimaat op veel afdelingen waar weinig ruimte is voor reflectie, gaan de meeste aios niet vanzelf een reflectieve leerhouding ontwikkelen. De opleider moet de aios daarom aanzetten tot reflectie op het eigen leren en functioneren. ${ }^{12}$ In de volgende paragraaf wordt behandeld welke strategieën de opleider bij het voortgangsgesprek kan gebruiken voor het stimuleren van reflectie bij de aios en hoe het portfolio dit kan ondersteunen.

\section{Coachingsstrategieën voor het voortgangsgesprek}

Korthagen ontwierp het ALACT model (Action, Looking back, Awareness, Creating alternative methods, Trial - Figuur 2) om de denkstappen van een effectieve lerende te beschrijven, die geconfronteerd wordt met een situatie waarvoor geen routineoplossing beschikbaar is. ${ }^{13}$

\section{A. ALACT - actie}

De cirkel start met een actie, in het algemeen een actie die niet succesvol verliep of waarbij iets onverwachts gebeurde. Met andere woorden: een situatie waarin de aios niet kon terugvallen op een routine oplossing.

\section{B. ALACT - terugkijken op de actie: zelf- beoordeling}

Hierna volgt een stap waarin de aios gestimuleerd wordt om gericht terug te kijken naar hoe hij of zij functioneerde. Dit kan in een bepaald patiëntcontact of andere situatie zijn, maar het terugkijken kan ook op de ontwikkeling van een bepaalde com- 


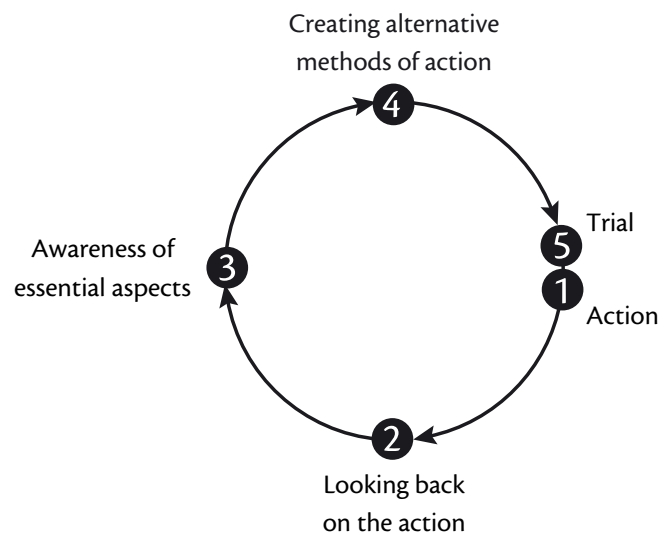

Figuur 2. Het ALACT model.

petentie in de voorgaande periode. Terugkijken gaat vergezeld met een evaluatie of gestelde doelen gehaald zijn en wat de bijdrage van de lerende zelf hieraan is. Dit kan worden beschouwd als een vorm van zelfbeoordeling. Een literatuurstudie naar de kwaliteit van zelfbeoordeling van artsen al of niet in opleiding laat zien dat zelfbeoordelingen vaak gebiased zijn. ${ }^{14}$ Eva en Regehr ${ }^{15}$ benadrukken dat het belangrijk is om zelfbeoordelingen zoveel mogelijk te schragen op externe beoordelingen. Het is belangrijk dat de opleider de aios stimuleert expliciet op zoek te gaan naar feedback en andere informatiebronnen die relevant kunnen zijn voor het leerproces. Dit is belangrijk om sturing te kunnen geven aan de verbetering van het functioneren, wat behulpzaam is bij het vaststellen van een juist zelfbeeld.

De rol van het portfolio: Als het portfolio is bijgehouden dan is het een rijke feedbackbron met zowel externe beoordelingen als zelfbeoordelingen. Om de kwaliteit van de zelfbeoordeling te bevorderen is het belangrijk te beschikken over een variatie aan bronnen en variatie aan beoordelingen. De validiteit van de zelfbe- oordeling wordt gemaximaliseerd als de zelfreflectie van de lerende overeenkomt met alle andere informatie die in het portfolio aanwezig is.

Onderzoek heeft aangetoond dat de opleider een beslissende rol kan spelen in het succesvol laten verlopen van het gebruik van portfolio's in het onderwijs. ${ }^{16}$ Uiteindelijk mogen aios van hun opleiders verwachten dat er serieus gekeken wordt naar het portfolio; ze hebben immers veel tijd en energie besteed in het samenstellen van het portfolio. Maar misschien nog belangrijker: een zorgvuldige analyse van het eigen functioneren van de aios kan voor hem/haar confronterend zijn. Het is belangrijk dat de opleider de aios hierbij begeleidt.

Coachingsstrategieën: Strategieën voor het stimuleren van het vragen naar feedback zijn: 1) zorg voor een veilige leeromgeving, 2) stimuleer concreetheid (de meeste mensen hebben de neiging om in algemene termen over hun eigen of andermans functioneren te praten), 3) stimuleer het gebruiken van de informatie in het portfolio en 4) stimuleer een breder perspectief dan het eigen gezichtspunt. 


\section{ALACT - bewustwording van essentiële aspecten: reflectie}

Nadat conclusies getrokken zijn over de kwaliteit van het functioneren, is de volgende stap in het ALACT model het bevorderen van reflectie. In deze fase tracht de aios nieuw en beter inzicht te krijgen in wat er gebeurd is, met andere woorden te reflecteren op het eigen gedrag. In deze fase wordt kritisch naar de beschikbare feedback en informatie gekeken op aanwezigheid van mogelijke patronen en is gericht op het identificeren van oorzaak en gevolg.

Er kan gefocust worden op de middelen die gebruikt zijn om een doel te bereiken waarbij aan de orde komt of de gebruikte strategie een juiste was of niet. Ook kan in overweging genomen worden of er wel een geschikt doel was geformuleerd, gelet op de specifieke situatie. De lerende kan zich eveneens afvragen wat bereikt moet worden vanuit een moreel of ethisch perspectief.

De rol van het portfolio: Taal is belangrijk bij het ondersteunen van het denken. Door dingen op te schrijven kan de reflectie worden gestimuleerd. ${ }^{13}$ Het toevoegen van een schriftelijke reflectie in het portfolio heeft het voordeel dat het voort kan komen uit de zelfbeoordeling welke op haar beurt gevalideerd wordt door externe beoordelingen in het portfolio. Hierbij spreekt men wel van 'gefaciliteerde reflectie. ${ }^{17}$ De aios kan het bewijs ook gebruiken om de reflectie met concrete voorbeelden te onderbouwen.

Coachingsstrategieën: $\mathrm{Om}$ aios te stimuleren te reflecteren en te leren van hun ervaringen hoeven mentoren niet alle goede antwoorden op vragen paraat te hebben. Het belangrijkste is dat mentoren de goede vragen stellen.

\section{ALACT - ontwikkelen of identificeren van alternatieve methoden voor het handelen: verandering}

Het analyseren van eerder gedrag kan een zoektocht naar alternatieve strategieën induceren of het verlaten van oorspronkelijke doelen. Het is belangrijk de nieuwe doelen en alternatieve strategieën te expliciteren. Een recent onderzoek toonde aan dat het stellen van doelen het leren stimuleert en dat een mentor (of opleider) een belangrijke rol vervult in dit opzicht. ${ }^{18}$ Lerenden die werken met een mentor formuleren meer specifieke doelen en verbeteren meer dan lerenden die geen mentor hebben. ${ }^{19}$ Vaak worden doelen die bereikt moeten worden, en wat daarvoor aan het functioneren moet worden veranderd, vastgelegd in een persoonlijk ontwikkelingsplan (POP).

De rol van het portfolio: Snadden en Thomas ${ }^{20}$ stelden vast dat als een portfolio wordt gebruikt voor de persoonlijke ontwikkeling en voor het vastleggen van de voortgang van aios, het belangrijk is een leerplan toe te voegen aan het portfolio.

Coachingsstrategie: Zowel de aios als de opleider moet zich committeren aan de afspraken binnen het persoonlijk ontwikkelingsplan (POP). Deze afspraken zijn agendapunten voor het volgende voortgangsgesprek. De plannen in een POP zijn vaak te vaag geformuleerd. Het is belangrijk dat de opleider de aios stimuleert zo concreet mogelijk te zijn. Het is aan te bevelen de leerdoelen 'SMART' te formuleren.

\section{E. ALACI - uitproberen}

De laatste stap in de ALACT cyclus is het uitproberen van 'nieuw' gedrag. Dit is eveneens de start van een nieuwe cirkel in de spiraal van de professionele ontwikkeling binnen dit model. 


\section{Tot slot}

Samengevat moet een opleider in staat zijn feedback te geven en het denken van de aios over zichzelf te ondersteunen door het stellen van vragen en door het creëren van een uitdagende, maar tegelijk ook veilige omgeving. ${ }^{11}$

De tijd die de opleider en de aios besteden aan de voorbereiding en het voeren van het gesprek is een van de belangrijkste factoren voor de effectiviteit van het gesprek. ${ }^{21}$ Door tijdgebrek kan het voortgangsgesprek erbij inschieten of er even bij gedaan worden. Een dergelijk gesprek is dan in feite inefficiënt omdat het niet het doel bereikt (i.c. het registreren van de voortgang)

\section{Literatuur}

1. Brand PLP, Boendermaker PM, Venekamp R, editors. Klinisch onderwijs en opleiden in de praktijk. Houten: Prelum uitgevers, 2010.

2. Stamm M \& Buddeberg-Fischer B. The impact of mentoring during postgraduate training on doctors' career success. Med Educ 2011; 45: 488-96.

3. Straus SE, Chatur F \& Taylor M. Issues in the mentor-mentee relationship in academic medicine: a qualitative study. Acad Med 2009; 84:135-9.

4. Memon, B \& Memon, MA. Mentoring and surgical training: a time for reflection! Adv Health Sci Educ Theory Pract 2010;15:749-54.

5. Ramanan RA, Taylor WC, Davis RB \& Phillips RS. Mentoring matters. Mentoring and career preparation in internal medicine residency training. J Gen Intern Med 2006; 21:340-5.

6. Overeem K, Driessen EW, Arah OA, Lombarts KM, Wollersheim HC \& Grol RP. Peer mentoring in doctor performance assessment: strategies, obstacles and benefits. Med Educ 2010;44: 140-7.

7. Cavalcanti RB, Detsky AS. The Education and Training of Future Physicians: Why Coaches Can't Be Judges. JAMA 2011;306(9):993-994.

8. Teunissen PW, Scheele F, Scherbier AJJA, Van der Vleuten CPM, Boor K, van Diemen-Steenvoorde JAAM. How residents learn: qualitative evidence for the pivotal role of clinical activities. Med Educ 2007;41:763-770.

9. Ericsson KA \& Charness N. Expert performance: its structure and acquisition. Am Psych 1994;49: 725-46.

10. Jarvis P. Reflective practice and nursing. Nurse education 1992;12:174-81.
11. Driessen E, van Tartwijk J \& Dornan T. The self critical doctor: helping students become more reflective. BMJ 2008;336:827-30.

12. Ertmer PA \& Bewby TJ. The expert learner: strategic, self-regulated, and reflective. Instructional Science 1996;24:1-24.

13. Korthagen FAJ, Kessels J, Koster B et al. editors. Linking theory and practice: the pedagogy of realistic teacher education, Lawrence Erlbaum Associates, Mahwah, NY, 2001.

14. Davis DA, Mazmanian PE, Fordis M et al. Accuracy of physician selfassessment compared with observed measures of competence: a systematic review, JAMA 2006;296(9):1094-1102.

15. Eva, KW \& Regehr G «I'll never play professional football» and other fallacies of self-assessment. J Contin Educ Health Prof 2008;28:14-9.

16. Driessen EW, van Tartwijk J, Van der Vleuten CPM et al. Portfolios in medical education: why do they meet with mixed success? A systematic review, Med Educ 2007; 41(12):1224-1233.

17. Conlon M. Appraisal: the catalyst of personal development, BMJ 2003;327:389-391.

18. Shute VJ. Focus on formative feedback. Rev Educ Res 2008;78(1):153-189.

19. Smither JW, London M, Flautt R et al. Can working with an executive coach improve multisource feedback ratings over time? A quasi-experimental field study. Pers Psychol 2003;56:23-44.

20. Snadden D and Thomas ML. The use of portfolio learning in medical education. Med Teach 1998;20(3):192-199.

21. Sambunjak D, Straus SE \& Marusic A. Mentoring in academic medicine: a systematic review. JAMA 2006;296:1103-15.

De auteurs:

Dr. E. Driessen is universitair hoofd docent medische onderwijskunde, Faculty of Health Medicine and Life Sciences van de Universiteit Maastricht.

Prof. dr. G. Kenter is gynaecoloog en hoofd Centrum Gynaecologische Oncologie, Amsterdam.

Drs. B. de Leede is onderwijskundige, LUMC en Rijnlandziekenhuis, Leiden.

Dr. J. Middeldorp is gynaecoloog, LUMC, Leiden.

Prof. dr. F. Scheele is gynaecoloog en opleider in het Sint Lucas Andreas Ziekenhuis, Amsterdam.

Dr. S. van Luijk is arts en onderwijskundige, Instituut voor Onderwijs en Opleiden, VUmc, Amsterdam. Prof. dr. Th.J. ten Cate is hoogleraar medische onderwijskunde en directeur Expertisecentrum voor Onderwijs en Opleiding, UMC Utrecht. 
Correspondentieadres:

Dr. E. Driessen, Faculty of Health Medicine and Life

Sciences, University Maastricht, postbus 616, 6200 MD

Maastricht.E-mail:e.driessen@maastrichtuniversity.nl

Belangenconflict: geen gemeld

Financiële ondersteuning: geen gemeld 